\title{
Analysis and Design Interfacing Circuit to Implement Industrial VFD in Photovoltaic Water Pumping
}

\author{
Ghida Alnassan \\ Post Graduate Student (MSC) \\ Faculty of Electrical \& Electronics \\ Engineering University of \\ Aleppo/Syria
}

\author{
Ahmmed Sharam, PhD \\ Professor \\ Faculty of Electrical \& Electronics \\ Engineering University of \\ Aleppo/Syria
}

\author{
Wasim Habra, PhD \\ Teacher \\ Faculty of Electrical \& Electronics \\ Engineering University of \\ Aleppo/Syria
}

\begin{abstract}
Solar water pumping system is a practical and necessary solution for rural areas far from the public electricity grid.

There are many studies on solar water pumping systems, but what distinguishes this research is that it provides a modeling and simulation of the control circuit of a water pump driven by a three-phase induction motor (IM) fed from photovoltaic panels so that the induction speed is controlled by the motor from the moment of starting Turn it on at sunrise to the moment it stopped at sunset, so that the frequency changes from $(0 \mathrm{~Hz})$ to $(50 \mathrm{~Hz})$ depending on the change of radiation and temperature in proportion to the motor's input voltage, so that the ratio $(\mathrm{V} / \mathrm{F})$ remains constant, using Control algorithm variable frequency drive (VFD), also was used efficient of solar energy by operating Photovoltaic (PV) panels at maximum power point tracking (MPPT) for powering the water pump.
\end{abstract}

Thise circuit is simulated using MATLAB.

\section{General Terms}

Solar PV, maximum power point tracking (MPPT), Proportional Derivative Controller (PID), three-phase induction motor

\section{Keywords}

SPWM, VFD, PID, Boost converter

\section{INTRODUCTION}

In remote rural areas, a large amount of water is needed housing, agricultural and animal services, but these areas face difficulty in obtaining water due to the difficulty in obtaining electricity, whether from the public network or by fuel due to dimension and transportation costs. Therefore, off grid PV pumping systems are a very suitable solution, environmental and economical [1].

DC motors were used in the field of solar pumping systems in the past, due to their ease of control, but due to the rapid development of electronic and semiconductor sciences, methods of controlling the induction motor speed became easy and economical. For this reason, induction motors have replaced DC motors and become the most used because they are cheap, small and uncomplicated motors compared to DC motors [2]. There are several methods of regulating the rotational speed, including changing the number of motor poles, changing the electrical frequency of the source, changing the rotor resistance, and changing the value of the applied voltage on the stator coil, and the method $(\mathrm{V} / \mathrm{F}=$ Const) which conseder is one of the most common and used speed control methods[3].
Generally in solar pumping systems which driven by induction motors it must converting the DC current generated from the solar panels into alternating current using a voltage source inverter (VSI) to control the motor speed, And It is always recommended that PV panels operate at a Maximum Power Point (MPP) which provides an option to use PV energy efficiently [4].

In this paper, modeling and simulation of the control system of a water pump driven by a three-phase induction motor feed from PV array, in MATLAB environment

This model aims to simulate several phenomena at the same time (change of rotor speed and the corresponding change in operating frequency and voltage in a constant proportion, as well as change in solar radiation and temperature, and measuring torque for each case), which makes this work very suitable for all applications that require an induction motor Three phase to operate with variable torque such as solar irradiance and temperature change, achieving high costeffectiveness in all weather and technical operating conditions, and ensuring efficient motor operation using three MPPT, SPWM and VFD technologies.

Figure (1) shows the block diagram of a solar pumping system driven by a 3 -phase induction motor.

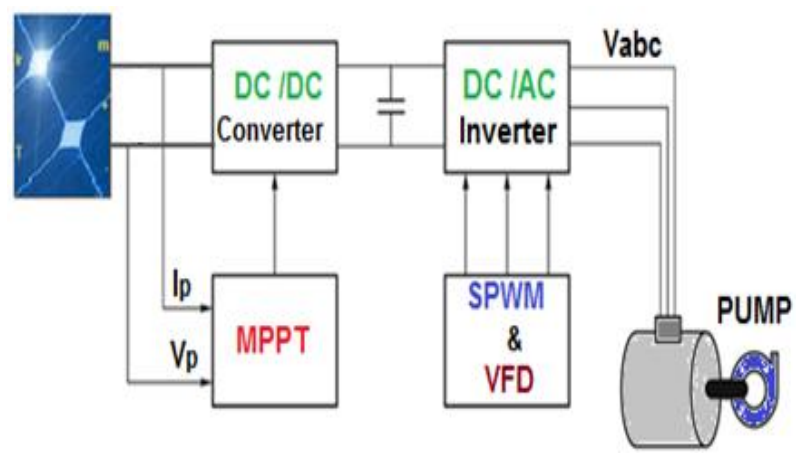

Fig 1: Control system block diagram

\subsection{V/f Control of Induction Motor}

Variable frequency drive (VFD) is a type of motor control device that drives an electric motor by changing the frequency and voltage supplied to the electric motor. The VFD can be used to raise or lower the motor speed. This technology reduces energy consumption and energy costs, extends equipment life, reduces maintenance, and increases production by achieving a high degree of carefully thought out control[5].

There are two basic types of this inverter control technology: 
1- Open loop numerical control: (the output is generated based on inputs)

2- closed loop numerical control: (the output is maintained at a level so that there is no difference between the process variable and the set point).

Open loop numerical control is the most used method for controlling the speed of induction motor due to the simplicity of its implementation, but closed loop numerical control gives better response to the system as a whole, especially with Continuous changes in system performance [6]

In both ways, the ratio must be maintained $(\mathrm{V} / \mathrm{F}=$ Constant $)$ in order for the magnetic flux to remain constant[7].

\subsection{PID Controller}

The PID controller can be used for process control. The connection of PID desired set value and PID real value of the application with the functions of the variable frequency drive enables process control without further components. In this way, VFD applications such as pressure, volume flow or speed control can be implemented easily [8].

Today, most automation applications use closed-loop topology with controllers that can be P, PI, or PID [9].

In Fig. 2 are illustrated the block diagrams of closed loop systems with PID controllers. The system control signal $u$ is formed entirely from the error e eq.(1)

$$
e=r-y
$$

where $r$ is the command signal, called the reference signal, or the setpoint and $y$ is the process output signal.

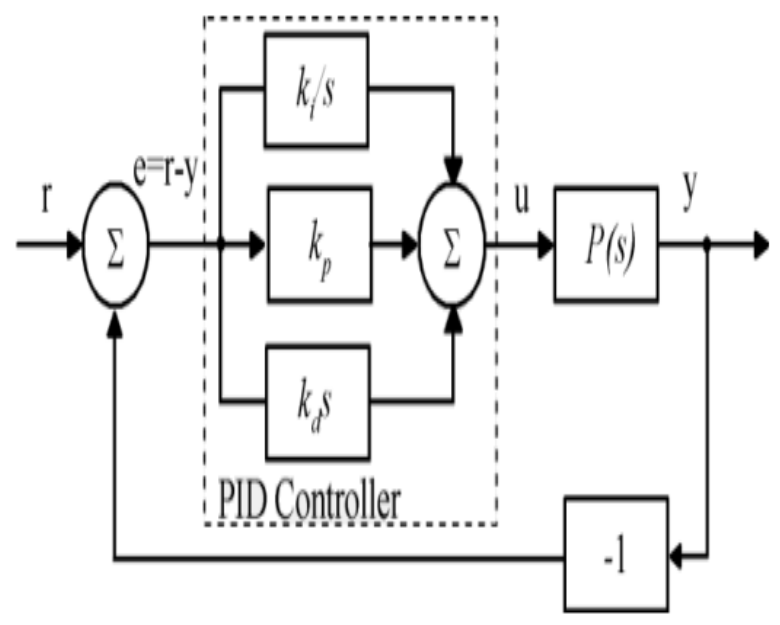

Fig 2: Control system block

The relation between input and output signals for an ideal PID controller with error feedback (Fig.2) is presented in eq.(2):

$$
\begin{aligned}
u & =K p e+K i \int_{0}^{t} e(\tau) d(\tau)+K d \frac{d e}{d t} \\
& =K p\left(e+\frac{1}{T i} \int_{0}^{t} e(\tau) d \tau+T d \frac{d e}{d t}\right)
\end{aligned}
$$

Where the PID controller action control is the sum Three terms: proportional Feedback, the Integrated Term, and
Derivative action, controllers were originally called the three controllers. Control unit parameters are: Relative gain $\mathrm{kp}$, integral gain $\mathrm{ki}$, or time integral The constant $\mathrm{Ti}$ and the derivative gain $\mathrm{kd}$, or the time of the derivative $\mathrm{Td}$ constant [10].

\section{SIMULATION AND RESULTS}

\subsection{Modeling SPWM technique}

To control the motor's frequency, the method of opening and closing transistors was changed by making them slower or faster. But was also have to change the voltage in order to maintain the ratio $\mathrm{v} / \mathrm{f}=$ const, this is called sinusoidal pulse width modulation (SPWM) technique. Three SPWM waveforms is obtained by comparing a triangular waveform of high frequency with three modulated waveforms offset $120^{\circ}$ each other as follows:

$$
\begin{gathered}
V a=m a \sin (w t) \\
V b=m a \sin (w t-120) \\
V c=m a \sin (w t-240)
\end{gathered}
$$

Whereas, ma is the modulation index and its value ranges within the range $[0.1 \rightarrow 1][11]$.As a result, three pulses were obtained to run three transistors, and then each of these pulses generated via the NOT circuit was reversed to lock the pulse to the remaining three transistors as shown in Figure 3, and in this way six transistors control pulses were obtained, offset About 60 degrees apart, and as a result of working the six transistors together we get the SPWM signal which filters through the windings of the induction motor to obtain a threephase sinusoidal signal.

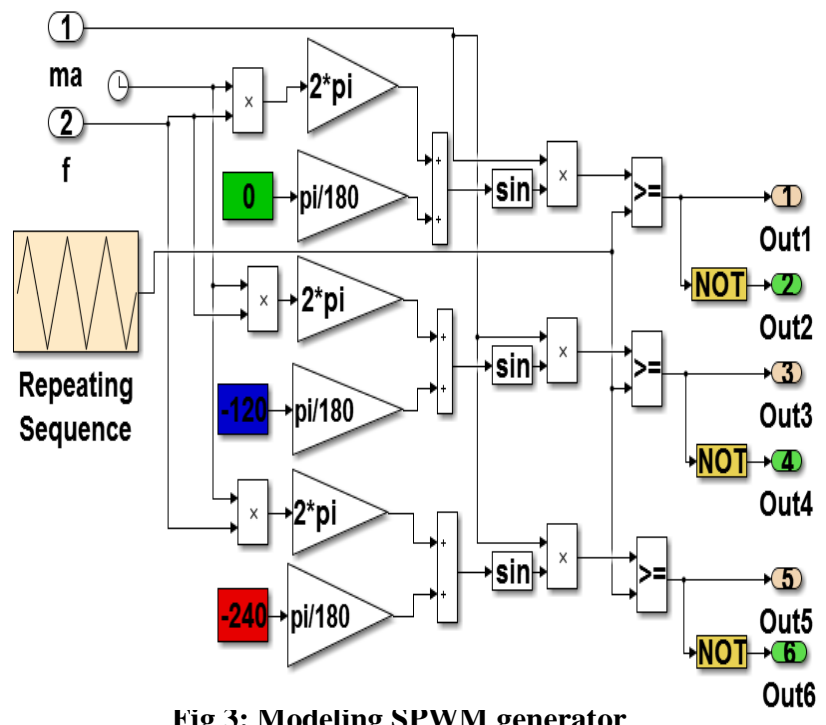

\subsection{Open-Loop V/f Control of Induction Motor using MATLAB}

The speed in an induction motor (Ns) is related to the number of pole pairs $(\mathrm{p})$ and the operating frequency $(\mathrm{F})$ according to the relationship

$$
N S=\frac{120 * F}{P}
$$

The main goal of this technique $\mathrm{V} / \mathrm{F}$ is to keep the ratio $\mathrm{V} / \mathrm{F}=$ const., which keeps the magnetic flux constant, and thus better control the induction motor.This ratio is determined as follows: Considering the nominal voltage of the motor used is 
$400 \mathrm{~V}$ and the nominal frequency value is $50 \mathrm{HZ} \&$ modification factor ma $=1$, then ratio will be

$$
\frac{m a}{F}=\frac{1}{50}=0.02
$$

However, this technique is fail to give sufficient torque at low frequencies because when a frequency less than a certain limit is applied, the torque will collapse, and then the motor will not be able to move the load, as a negligible drop in the stator voltage compared to the input voltage, so it must be compensated This voltage drop is achieved by adding a very simple increase in the modified amplitude this is known as voltage boosting [15] .

Was programmed eq.(6) \& eq.(7) using Matlab function in order to apply the V/F technology, and then was fed a threephase induction motor its nominal voltage $400 \mathrm{~V}$, its frequency $50 \mathrm{HZ}$, and its speed rated 1400 r.p.m by three- SPWM that working with the V/F technology, and was connected boost converter, which controlled of its work $\mathrm{P} \& \mathrm{O}$ algorithm,see fig.(5).

The fig.(6) shows the results of the system simulation when the motor running at nominal operating conditions where the maximum torque is kept constant within the speed range, while the fig.(7) shows that the maximum torque remains constant at different operating speeds (different frequencies).

\subsection{Modeling Maximum Power Point \\ Tracking P\&O Method}

There are several algorithms used to tracking the maximum power point generated from $\mathrm{pv}$ array, The advantages of $\mathrm{P} \& \mathrm{O}$ algorithm are simplicity and ease of implementation [12], The $\mathrm{P} \& \mathrm{O}$ MPPT algorithm which is shown in fig. 4 has been implemented in MALAB , it is senses the instantaneous PV voltage 'Vpv' and PV current 'Ipv'; then calculates PV power 'Ppv'. These values are averaged within a time period 'Tmod' and are stored as previous values $\operatorname{Vpv}(n-1)$ and $\operatorname{Ppv}(n-1)$. After one fundamental cycle the present PV voltage $\operatorname{Vpv}(n)$ and power $\operatorname{Ppv}(n)$ are obtained by averaging the instantaneous values. These present values and previously obtained values are compared to determine the operating region in the p-v curve as described in Eqs.( 8) and (9).

$\frac{P_{p v}(n)-P_{p v}(n-1)}{V_{p v}(n)-V_{p v}(n-1)}<0 \quad$ Then $D=D+\Delta D$

$\frac{P_{p v}(n)-P_{p v}(n-1)}{V_{p v}(n)-V_{p v}(n-1)}>0 \quad$ Then $D=D-\Delta D$
Usually a DC / DC converter is placed between the solar panel array and the load in order to eliminate unwanted effects from the solar panels and also to apply MPPT technology by it.usually used in solar PV systems boost converter is to boost the output voltage of the panels , or Buck converter, to reduce the voltage of the panels [13], and in some applications has been used a Buck-Boost converter [14] .In this application, the Boost converter was used because the purpose here is to raise the voltage generated by the PV panels, the output voltage $\mathrm{Vdc}$ is expressed by Eq, (10) :

$$
V o=\frac{V s}{1-D}
$$

Where $\mathrm{D}$ is a duty cycle ratio fixed by the MPPT algorithm, $\mathrm{Vo}$ is output voltage of boost converter,Vs is Solar panel voltage. Matlab function was used and programmed according to the $\mathrm{P} \& \mathrm{O}$ algorithm ,shown in Figure (4), for making the solar panels always operate at the maximum power point, which improves the system performance under the conditions of changing radiation and temperature .

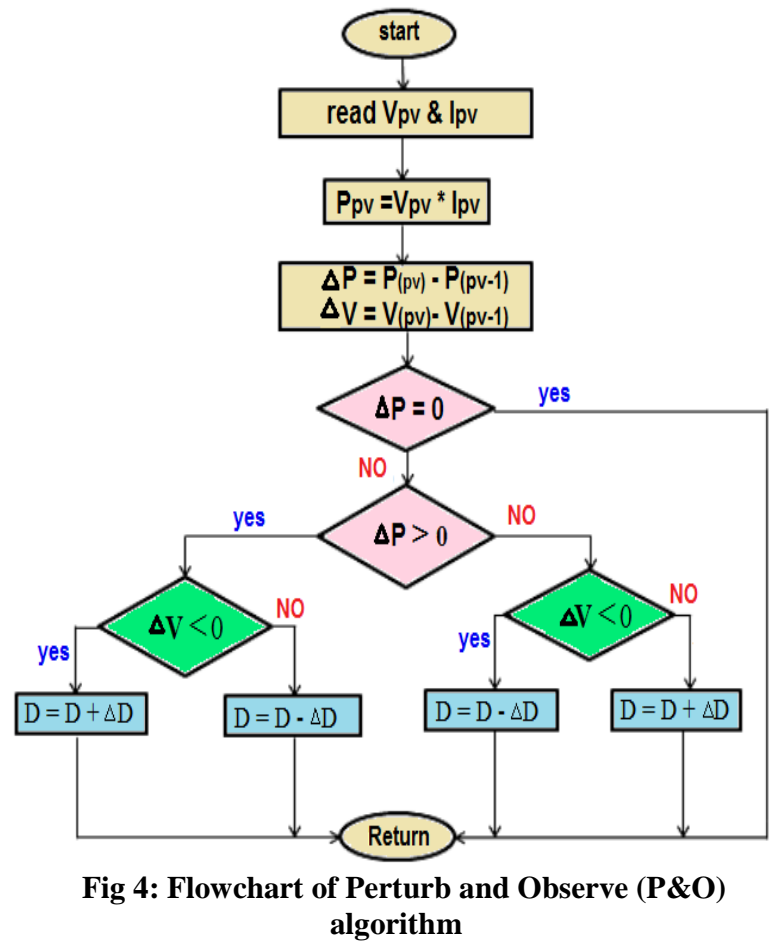




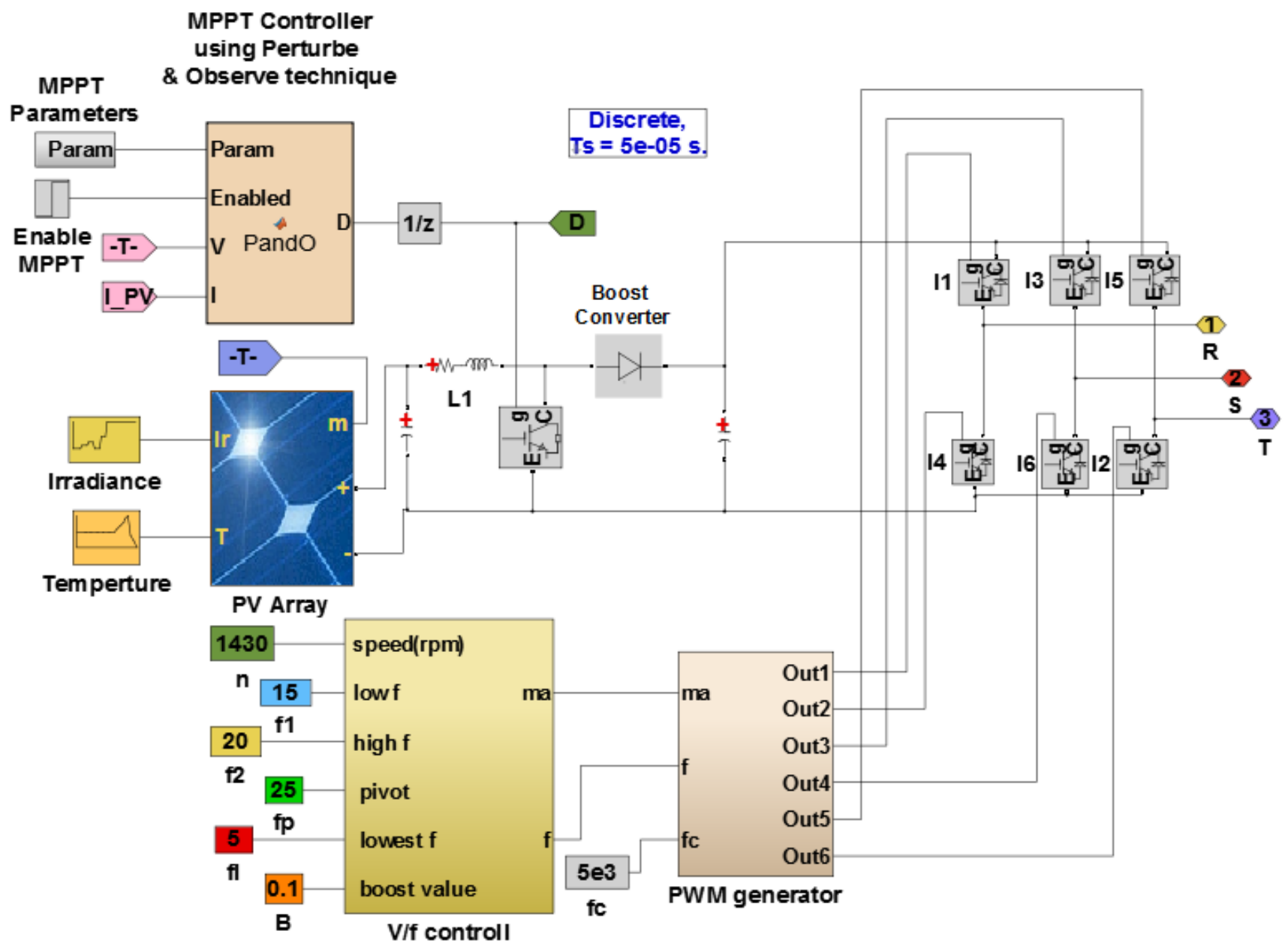

Fig 5: Modeling the solar pumping system driven by open-Loop V/F control, MPPT algorithm and PWM generator using
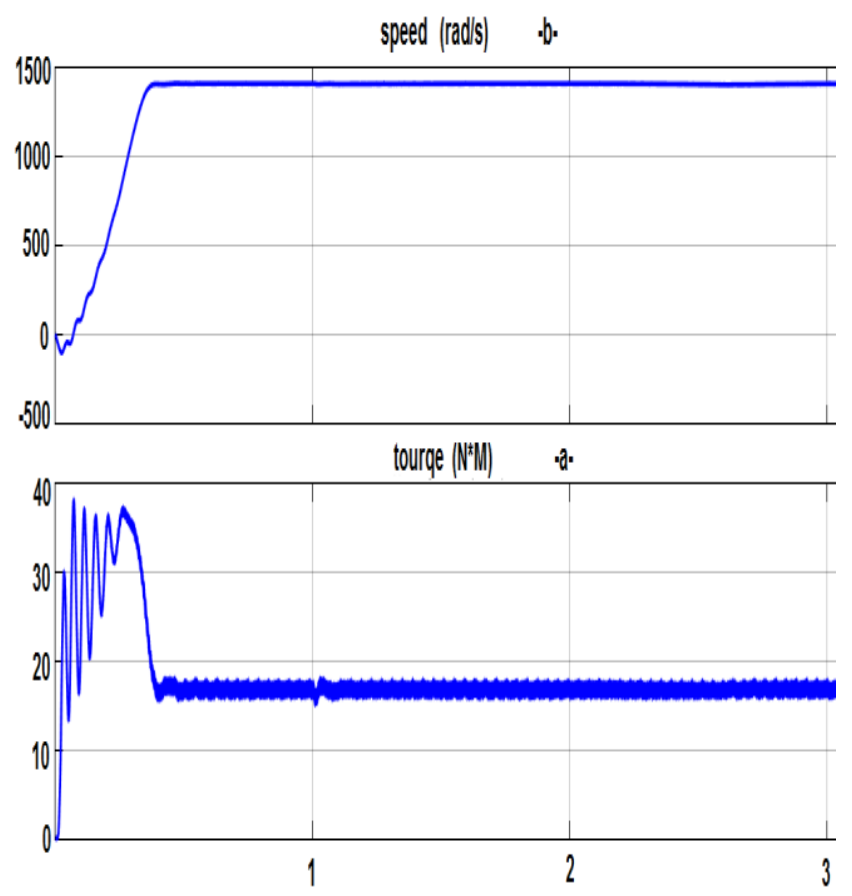
MATLAB

Fig6 : Simulation results of a system designed for Speed 1400 RPM (a) that keeps torque(b) constant regardless

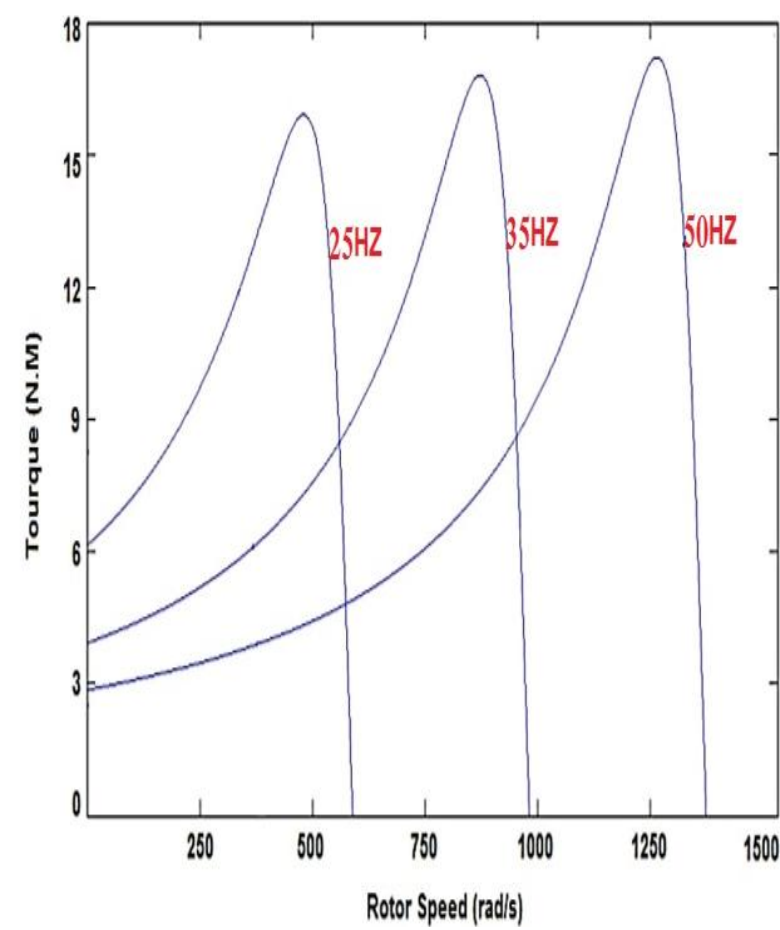
of weather conditions

Fig 7: The relationship of rotor speed with torque for different values of frequency 
Table 1. Simulation results of open-Loop V/F control at different speeds:

\begin{tabular}{|c|c|c|c|}
\hline $\begin{array}{c}\text { Frequency } \\
(\mathbf{H Z})\end{array}$ & $\begin{array}{c}\text { Modulation } \\
\text { index (ma) }\end{array}$ & $\begin{array}{c}\text { Rotor } \\
\text { speed } \\
(\mathbf{R . P . M})\end{array}$ & $\begin{array}{c}\text { Torque } \\
(\mathbf{N} * \mathbf{M})\end{array}$ \\
\hline 50 & 1 & 1417 & 17 \\
\hline 45 & 0.9 & 1260 & 17 \\
\hline 40 & 0.8 & 1115 & 17 \\
\hline 35 & 0.6 & 965 & 17 \\
\hline 30 & 0.5 & 810 & 17 \\
\hline 25 & 0.425 & 658 & 17 \\
\hline 20 & 0.7 & 520 & 17 \\
\hline 15 & 0.35 & 385 & 17 \\
\hline 10 & 0.275 & 255 & 17 \\
\hline 5 & 0.2 & 142 & 17 \\
\hline
\end{tabular}

Table 2. Simulation results of open-Loop V/F control at 1400 R.P.M with changing solar irradiance $\&$ temperature:

\begin{tabular}{|c|c|c|c|}
\hline \multicolumn{4}{|c|}{ results with changing solar irradiance: } \\
\hline $\begin{array}{c}\text { Solar } \\
\text { radiation } \\
\left(\mathrm{W} / M^{2}\right) \text { at } \\
25 C^{\circ}\end{array}$ & $\begin{array}{l}\text { VL-L of the } \\
\operatorname{motor}(V)\end{array}$ & $\begin{array}{c}\text { Rotor } \\
\text { speed } \\
\text { (R.P.M) }\end{array}$ & $\begin{array}{l}\text { Torque } \\
(\mathbf{N} * \mathbf{M})\end{array}$ \\
\hline 1000 & 40 & 1417 & 17 \\
\hline 800 & 397 & 1415 & 17 \\
\hline 600 & 392 & 1413 & 17 \\
\hline 400 & failed & failed & failed \\
\hline 200 & failed & failed & failed \\
\hline \multicolumn{4}{|c|}{ Results with changing temperature } \\
\hline $\begin{array}{c}\text { Solar } \\
\text { temperature } \\
\left(\mathrm{C}^{\circ}\right) \text { at } 1000 \\
\text { W/M }\end{array}$ & $\begin{array}{c}\text { VL-L of } \\
\operatorname{motor}(V)\end{array}$ & $\begin{array}{l}\text { Rotor speed } \\
\quad(\operatorname{Rad} / S)\end{array}$ & $\begin{array}{l}\text { Torque } \\
(\mathbf{N} * \mathbf{M})\end{array}$ \\
\hline 25 & 400 & 1417 & 17 \\
\hline 30 & 382 & 1408 & 17 \\
\hline 40 & 370 & 1400 & 17 \\
\hline 50 & 359 & 1392 & 17 \\
\hline
\end{tabular}

Noted from the table (1) that the maximum torque remains constant in any case of chang the speed, but in this model the speed is not controlled at all, it is only organized. On the other hand, noted from Table (2) that in conditions of low radiation the model fails to stably drive the motor, So was used closed-loop V/f Control, to control of speed rotor Better.

\subsection{Closed-Loop V/f Control of Induction Motor using MATLAB}

a PID loop was used to control the frequency at which the induction motor will operate by adjusting the voltage value, where the required voltage value (set point) and the actual voltage value generated from the electrophoresis panels are entered to the collection point (sum). These two signals are opposite in polarity and produce zero error or skew when the required voltage is equal to the actual voltage. If the value of the two signals differ, then the error signal will have a positive or negative value, depending on whether the actual voltage is greater or less than the required voltage. This error signal is input to the PID controller. It is necessary to note that in a water pump system with an induction motor the response time must be relatively large, so the derivative must be set equal to zero The PID output reacts the error and gives a frequency for reduce the error value to zero. Accordingly SPWM are generated to feed the inverter, So that the $\mathrm{V} / \mathrm{F}$ ratio remains constant. This keeps the flow value constant which in ensures maximum constant torque across Speed range.The table(3) shows the results of the final proposed design As the speed of the water pump is controlled efficiently. The figure(8) shows the final proposed model for feeding a Photovoltaic Water Pump driven by a three-phase induction motor,the figures(9),(10),(11),(12),(13),(14),(15) show the end results.

Table 3. Model simulation results of open:

\begin{tabular}{|c|c|c|c|c|}
\hline $\begin{array}{l}\text { Frequency } \\
(\mathrm{HZ})\end{array}$ & $\begin{array}{l}\text { modification } \\
\text { factor ( } \mathrm{ma} \text { ) }\end{array}$ & $\begin{array}{c}\text { Solar } \\
\text { radiation } \\
\left(\mathrm{W} / M^{2}\right) \\
\text { at } 25 \mathrm{C}^{\circ}\end{array}$ & $\begin{array}{c}\text { Torque } \\
\left(N^{*} M\right)\end{array}$ & $\begin{array}{c}\text { Rotor } \\
\text { speed } \\
(\text { R.P.M })\end{array}$ \\
\hline 50 & 1 & 900 & 17 & 1400 \\
\hline 45 & 0.9 & 800 & 15 & 1200 \\
\hline 40 & 0.8 & 600 & 13 & 1000 \\
\hline 35 & 0.7 & 500 & 10 & 900 \\
\hline 30 & 0.6 & 400 & 7 & 800 \\
\hline 25 & 0.5 & 300 & 5 & 700 \\
\hline 20 & 0.425 & 200 & 4 & 600 \\
\hline 15 & 0.35 & 200 & 0 & 400 \\
\hline 10 & 0.275 & 100 & 0 & 200 \\
\hline 5 & 0.2 & 100 & 0 & 200 \\
\hline
\end{tabular}




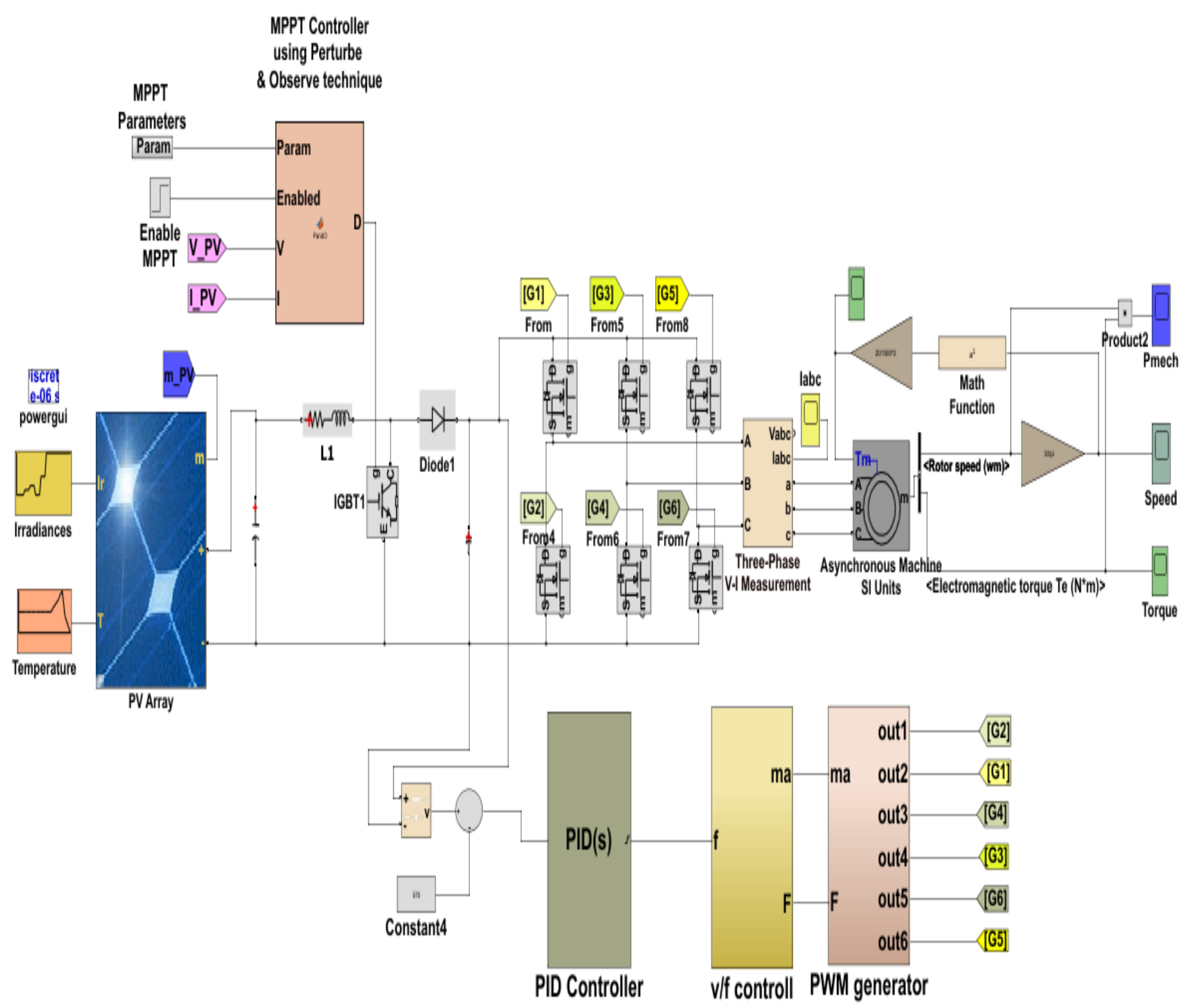

Fig 8: Modeling the solar pumping system driven by Closed-Loop V/F control and MPPT algorithm in using MATLAB

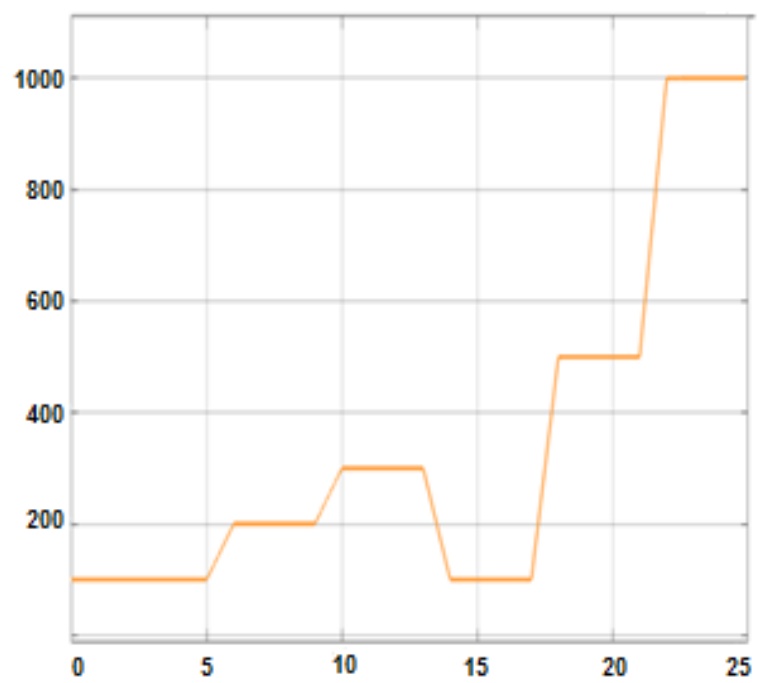

Fig9: radiation change with time.

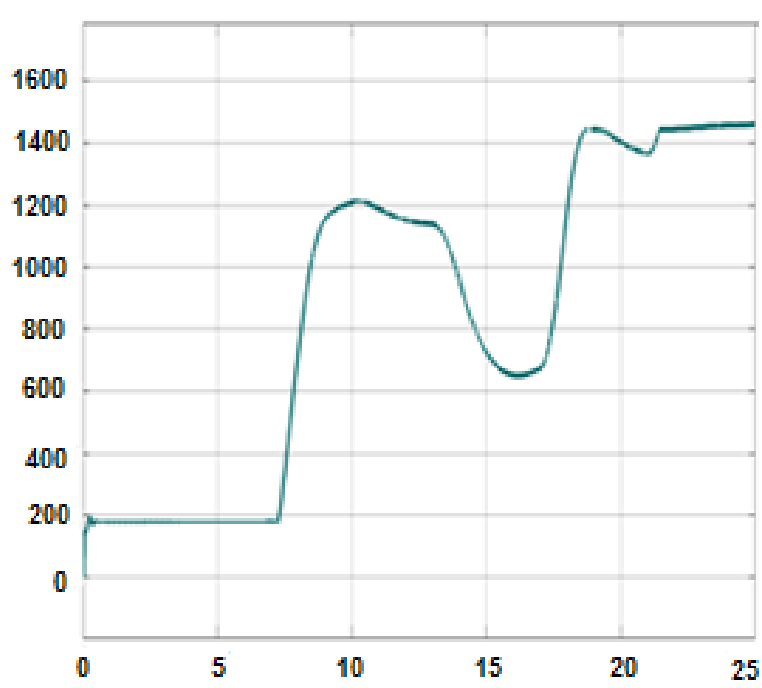

Fig 10: Pump Speed Change with T'ime 


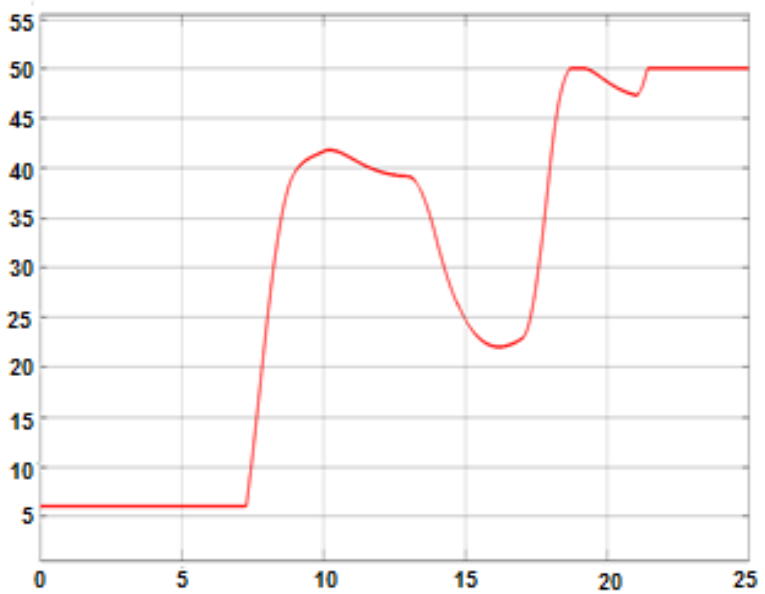

Fig 11: frequency change with time.

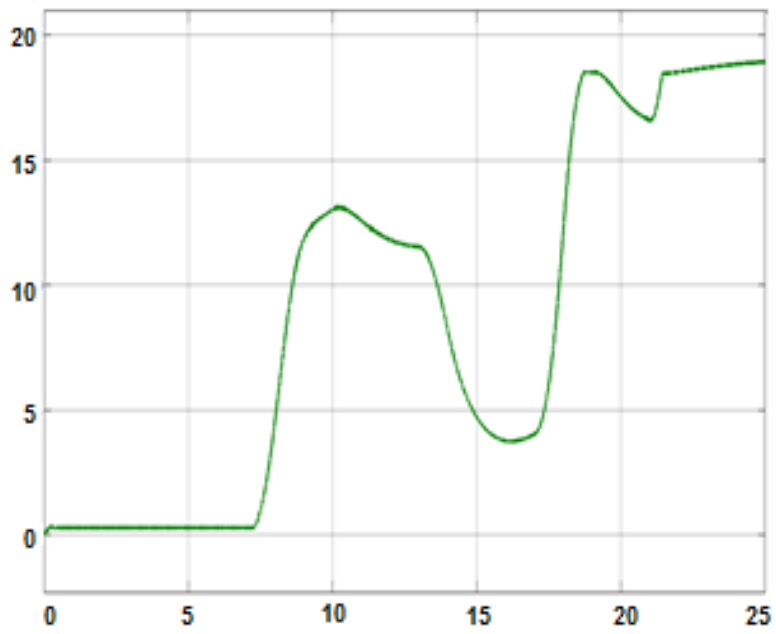

Fig 12: Torque change with time.

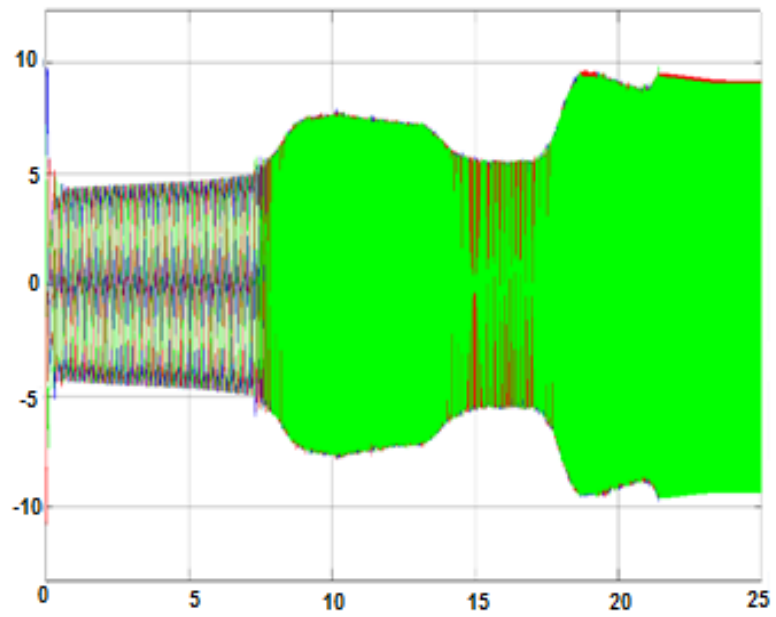

Fig13: Three-phase current change with time.

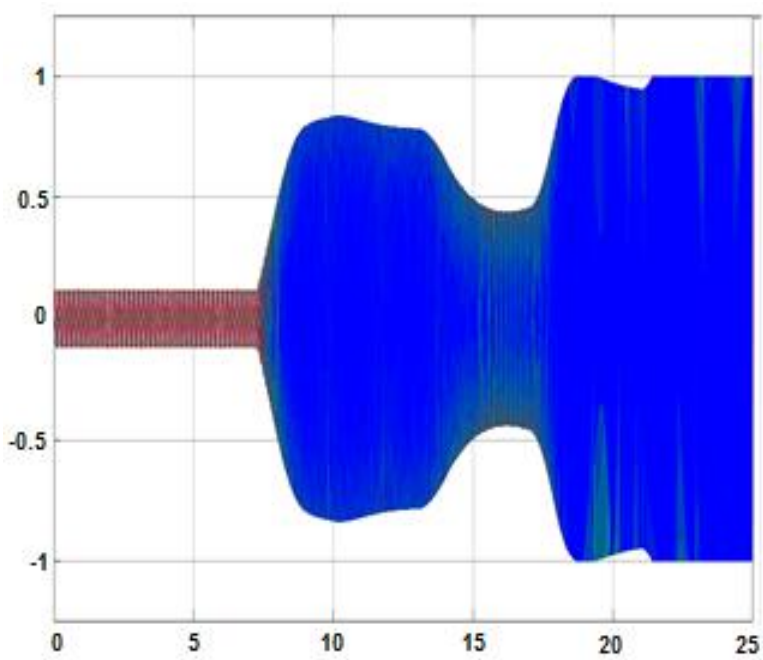

Fig 14: Modulation index (ma) changes with time.

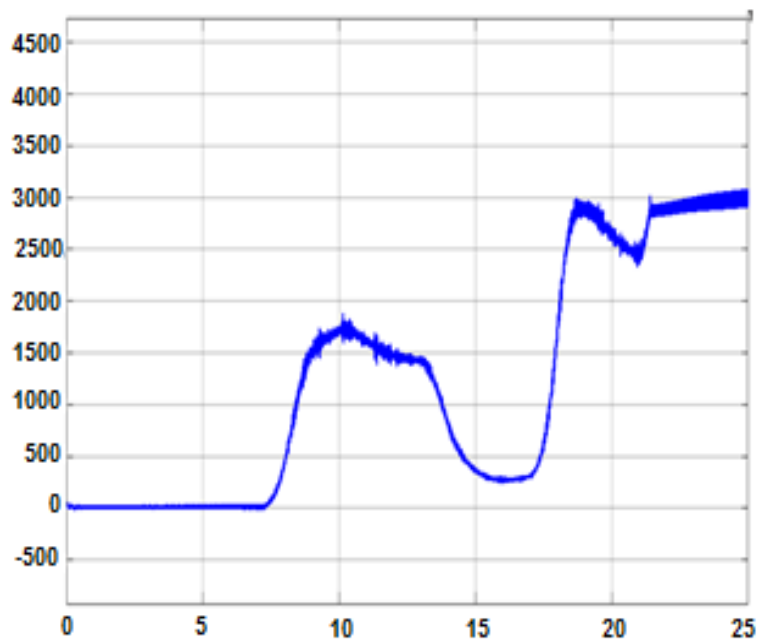

Fig 15: Water flow with time change.

\section{COMPARE RESULTS}

The solar water pumping system is modeled and simulated, using three technologies (V / F control technology, SPWM technology , and The P\&O MPPT algorithm). The design of solar pumping system driven by open-Loop V/F control Fig. (5) gives good control of the three-phase induction motor when setting a specific speed value, but it lacks the process of controlling the speed, also it fails to drive the solar pump in the case of low radiation .So was design in Fig (8) solar pumping system driven by Closed-Loop V/F control to control of speed of the induction motor, and thus control of the abundance of water pumping was achieved by means of Addition of a PID controller, which proved during the simulation that the control mechanism achieves the highest and best performance of the pump according to different weather conditions, including radiation and temperature.

This control circuit is characterized by its low cost,as the speed, frequency, torque and Water flow can be achieved without the presence of sensors, and according to the change of the voltage generated by solar panels throughout the day, control process can be achieved without the presence of sensors. 
This circuit can be successfully utilized to suit all industrial applications that require use of an induction motor fed from the PV array, as it enables to take advantage of the maximum power generated by the solar panels while achieving safe motor operation.

\section{REFERENCES}

[1] Rayyan Azam Khan, Liaquat Ali Khan*, Syed Zahid Hussain. 2015 . Design and Simulation of $0.75 \mathrm{hp} \mathrm{Soft}$ Start AC Water Pump Powered by PV Solar System.

[2] Ch. Madhan mohan, V.S.Vakula \& R.S R Krishnam Naidu. 2014. V/F SPEED CONTROL OF SOLAR PV SYSTEM FED INDUCTION MOTOR DRIVE. International Journal of Latest Trends in Engineering and Technology.

[3] T. Muthamizhan and R. Ramesh .2013. Design and Simulation of PV driven three phase Induction motorll. International Review on Modelling and Simulations.

[4] Najet REBEI, Ali HMIDET, Rabiaa GAMMOUDI, Othman HASNAOUI .2015. Implementation of photovoltaic water pumping system with MPPT controls.

[5] Atul Sharma, Dr. Arun Parakh.2017. DESIGN OF SOLAR POWERED INDUCTION MOTOR DRIVE FOR PUMPING APPLICATION.

[6] Steve Petersen.Variable Frequency Drive Control Methods .2014. Copyright Yaskawa America, Inc.
[7] WWW.VFDs,COM .

[8] V. A. Maraba, A. E. Kuzucuoglu, "PID Neural Network Based Speed Control of Asynchronous Motor using Programmable Logic Controller.

[9] Mihai Rata, Gabriela Rata.2016. A Solution for the Study and Understanding of PID Controllers

[10] Li, Y. and Ang, K.H. and Chong, G.C.Y. 2006. PID control system.

[11] Sumit K. Gupta, M. Rizwan Khan and Kaushar Jahan. (2013). Modeling,Analysis and Control of Solar WaterPumping System.

[12] Najet REBEI, Ali HMIDET, Rabiaa GAMMOUDI, Othman HASNAOUI. (2015). Implementation of photovoltaic water pumping system with MPPT controls

[13] Najet REBEI, Ali HMIDET, Rabiaa GAMMOUDI, Othman HASNAOUI. (2015). Implementation of photovoltaic water pumping system with MPPT controls.

[14] Sumit K. Gupta, M. Rizwan Khan and Kaushar Jahan., (2013)- Modeling,Analysis and Control of Solar Water Pumping System.

[15] Zhe Zhang, Student Member -.,(2018) - An Improved High-performance Open-loop V/f Control Method for Induction Machines. 